\title{
Metallothionein 2A genetic polymorphisms and risk of ductal breast cancer
}

\author{
Anna Krześlak • Ewa Forma • Paweł Jóźwiak • Agnieszka Szymczyk • \\ Beata Smolarz • Hanna Romanowicz-Makowska · Waldemar Różański • \\ Magdalena Bryś
}

Received: 19 March 2012/Accepted: 24 September 2012/Published online: 6 October 2012

(C) The Author(s) 2012. This article is published with open access at Springerlink.com

\begin{abstract}
Metallothioneins (MTs) are a family of metal binding proteins that play an important role in cellular processes such as proliferation and apoptosis. Metallothionein $2 \mathrm{~A}$ is the most expressed MT isoform in the breast cells. A number of studies have demonstrated increased MT2A expression in various human tumors, including breast cancer. We carried out an association study to examine whether MT2A gene polymorphisms are associated with risk of breast cancer. Information on lifestyle risk factors was collected via a self-administered questionnaire. Genotyping was conducted using polymerase chain reaction-restriction fragment length polymorphism technique. Three single nucleotide polymorphisms (SNP) rs28366003, rs1610216 and rs10636 were genotyped in 534 breast cancer cases and 556 population controls. One SNP in MT2A (rs28366003) showed a positive association with breast cancer. Compared with homozygous common allele carriers, heterozygous for the $\mathrm{G}$ variant [odds ratio $(\mathrm{OR})=1.92,95 \%$ confidence interval $(\mathrm{CI}): 1.28-2.81$, $p$ trend $<0.01$; the OR assuming a dominant model 1.93
\end{abstract}

Anna Krześlak and Ewa Forma contributed equally to this work.

A. Krześlak · E. Forma · P. Jóźwiak · A. Szymczyk · M. Bryś ( $ه)$ Department of Cytobiochemistry, University of Łódź, Pomorska 141/143, 90-236 Lodz, Poland

e-mail: zreg@biol.uni.lodz.pl

B. Smolarz · H. Romanowicz-Makowska Department of Clinical Pathomorphology, Polish Mother's Memorial Hospital Research Institute, Rzgowska 281/289, 93-338 Lodz, Poland

W. Różański

2nd Department of Urology, Medical University of Łódź, Pabianicka 62, 93-513 Lodz, Poland
(95\% CI: $1.29-2.89, p_{\text {dominant }}<0.02$ ) after adjustment for age, family history, smoking status, BMI, menarche, parity, menopausal status and use of contraceptive and menopausal hormones] had a significantly increased risk of breast cancer in Polish population, as well as women with haplotypes, including variant allele of rs28366003 SNP $(\mathrm{OR}=1.58, \mathrm{CI}: 0.41-6.33, p$ global $=0.03)$. Our data suggest that the rs28366003 SNP in MT2A is associated with risk of breast cancer in Polish population.

Keywords Metallothionein 2A $\cdot$ Breast cancer $\cdot$ SNP

\section{Introduction}

Metallothioneins (MTs) are a family of proteins with low molecular mass $(6-7 \mathrm{kDa})$, high content of cysteine and complete absence of aromatic amino acids [1-3]. MTs bind to biologically essential metals like $\mathrm{Zn}$ and $\mathrm{Cu}$ and can participate in regulation of these metals homeostasis. Moreover, MTs absorb the heavy metals such as $\mathrm{Cd}, \mathrm{Pb}$, $\mathrm{Hg}$ and As and assist with their transportation and extraction [1-4]. Apart from their role in protection of tissue against heavy metals, MTs can act as potent antioxidants against oxidative damages [1-4]. They are known to participate also in cell proliferation and apoptosis which are very important processes in carcinogenesis [5-7]. In human, MTs are encoded by a family of genes located on chromosome 16q13 consisting of ten functional MT isoforms. The encoded proteins are subdivided into four groups: MT1, MT2, MT3 and MT4 proteins. Human MT isoforms have tissue-specific expression patterns [3]. MTs expression increases in response to various inducers such as metals, interleukins, interferon, tumor necrosis factor alpha and glucocorticoid hormones [8]. 
A number of studies have demonstrated increased expression of MT1 and MT2 mRNA and protein in various human tumors such as kidney, lung, nasopharynx, ovary, prostate, salivary gland, testes, urinary bladder, cervical, endometrial, skin and pancreatic cancers as well as melanoma [7, 9, 10]. In some cases, high expression of MT1 and MT2 correlates with tumor grade/stage, chemotherapy resistance and poor prognosis. However, MT1/2 can also be down-regulated in certain tumors, for example, hepatocellular carcinoma and liver adenocarcinoma [7].

MT2A is the most expressed isoform in the breast cells. The MT2A mRNA expression is positively correlated with histological grade [7]. Histological grade 3 tumors were observed to have a higher expression of MT2A mRNA than grade 1 and 2 tumors. Immunohistochemical studies have shown that cytoplasmic and/or nuclear MT1/2 protein expression is associated with tumor grade, increased recurrence rate and poor survival in the highly malignant invasive ductal breast carcinomas [5, 7, 9, 10]. Some studies have shown an inverse correlation between MTs expression and progesterone and estrogen receptors positivity [11]. Based on correlation of MT expression and clinicopathological parameters of breast cancer showed in many reports, Bay et al. [12] suggested that metallothionein is a promising prognostic biomarker in breast cancer.

Taking into account the potential role of MT2A in breast carcinogenesis, we have analyzed an association between breast cancer and three known single nucleotide polymorphisms (SNPs) of MT2A gene. We selected SNPs that could potentially affect gene expression. The SNPs analyzed by us in this study concerned $A / G$ transitions in promoter region at loci -5 and -209 (rs28366003 and rs1610216, respectively) and C/G transition in 3'UTR region at locus +838 (rs10636). Therefore, we comprehensively evaluated the association of this SNP with breast cancer risk in a Polish population-based case-control study.

\section{Materials and methods}

\section{Study population}

This case-control study involved 534 women with invasive ductal breast cancer (age range 34-81, mean age $54.76 \pm 7.35$ ) recruited between May 2003 and November 2010. The patients had a confirmed diagnosis of ductal breast cancer based on histopathological evaluation and were under treatment at the Polish Mothers Memorial Hospital Research Institute, Lodz, Poland. None of the recruited patients received preoperative chemo- or radiotherapy. Patients with recurrence of breast cancer and patients who had previously diagnosed with other types of primary cancers (excluding skin cancer) were excluded.

A group of 556 healthy Polish individuals were collected from the Polish Mothers Memorial Hospital Research Institute from periodic health checkups and used as reference. They were non-related women who have never been diagnosed with breast tumors or other tumors and were randomly selected and matched to the cases on 10 years age groups (age range 34-83, mean age $51.27 \pm 11.18)$. We enrolled only Caucasian women born and living in central Poland (Łódź region). We queried the cancer registry database every 2 months and identified all histopathologically confirmed incident primary breast cancer cases reported within 4 months of diagnosis preceding the recruitment. Informed consent was obtained from patients and controls, and the Ethical Committee approved the study.

\section{Lifestyle risk factors}

Study participants were interviewed using questionnaire that included socio-demographic, health related information, smoking status, menstrual and reproductive histories and exogenous hormone use. A positive family history of breast cancer was defined as reporting of breast cancer in one or more first-degree relatives. Body mass index (BMI) was calculated from current weight in kilograms divided by height in meter square (measurements were extracted from patient's medical record). Smoking was grouped into "never," "former" and "current" based on self-reported usage. Participants who reported smoking at least 100 cigarettes in their lifetime and who, at the time of survey, smoked either every day or some days were defined as current smoker. Eight participants reported smoking at least 100 cigarettes in their lifetime but had not been smoking for 1-2 months. They were classified as current smoker. Participants who reported smoking at least 100 cigarettes in their lifetime and who had not been smoking for at least 3 months were defined as former smoker. Participants who reported never having smoked 100 cigarettes were defined as never smoker. Natural age at menopause was defined as the age at the last menstrual period, which can only be defined retrospectively after at least 12 consecutive months of amenorrhea. This last menstrual period should not be induced by surgery or other obvious causes, such as irradiation or hormone therapy. None of the women involved in the study had undergone a hysterectomy and oophorectomy. Regular drug use was defined as self-report use of oral contraceptives or menopausal hormones for 6 months or longer. For any missing survey data, patients were subsequently queried which lead to complete responses by all participants. 
Questionnaire and the matching techniques

An analysis of the computerized medical records identified 916 ductal breast cancer patients in the age group 30-85 years. From the same hospital registry of women undergoing periodic health checkups, a control population of 1,082 individuals in the same age group ( $30-85$ years) was randomly selected. A postal questionnaire was sent to both the cases and controls. The response rate in the survey for the ductal breast cancer patients was $58.3 \%$ and for the controls $56.3 \%$ thus leaving a group of $n=534$ cases and a population of $n=609$ controls. Finally, the study group was 534 cases and 556 controls.

Venipuncture, blood sample collection and genotyping

The larger median cubital, basilic or cephalic veins were selected and the tourniquet was applied 3-4 inches above the collection site. Next, the puncture site was cleaned by the $70 \%$ alcohol pad, $21 \mathrm{G}$ needle was inserted into a vein, and blood started to flow to collection tube with EDTA as an anticoagulant (lavender top). After blood collection, tube was inverted $8-10$ times and placed in refrigerator at $-20{ }^{\circ} \mathrm{C}$.

Blood samples obtained from the participants were stored at $-20{ }^{\circ} \mathrm{C}$ within $2 \mathrm{~h}$ of removal. DNA was isolated by standard method using proteinase $\mathrm{K}$ digestion, phenol chloroform extraction and ethanol precipitation.

The quantity and purity of the DNA extracts were assessed by spectrophotometry using the Helios Alpha UV-vis spectrophotometer system (Thermo Fisher Scientific Inc.). The absorbances at 230, 260 and $280 \mathrm{~nm}$ were measured in $2 \mu \mathrm{l}$ of each sample. Concentration of DNA was estimated by spectrophotometric quantification at $260 \mathrm{~nm}$. The overall purity was assessed by calculating the absorbance ratios $260 / 280$ and $260 / 230$. High values for both ratio $(260 / 280>1.8,260 / 230>2)$ are commonly accepted as good indicators for pure DNA.

PCR reactions were performed, using Perkin-Elmer DNA Thermal cycler 480, in a total volume of $50 \mu \mathrm{l}$ to amplify MT2A $-5 \mathrm{~A} / \mathrm{G},-209 \mathrm{~A} / \mathrm{G}$ and $+838 \mathrm{C} / \mathrm{G}$. The reaction mixtures consisted of $100 \mathrm{ng}$ of genomic DNA and the following set of primers: $10 \mu \mathrm{M}$ of MT2A $-5 \mathrm{~A} / \mathrm{G}$ primers (5'-GGGCCGCCTTCAGGGAACTG- $3^{\prime}$ and $5^{\prime}$-G GACTTGGAGGAGGCGTGGT-3') MT2A -209A/G primers (5'-GGCTCAGGTTCGAGTACAGG- ${ }^{\prime}$ and $5^{\prime}$-AAG TCACTTGCGGCTCCA-3') or of MT2A +838 primers (5'-CCGCTCCCAGATGTAAAGAA- $3^{\prime}$ and $5^{\prime}$-GGCATA TAAAGAAAACCAGAGACA-3'). The DNA samples were amplified in the presence of $200 \mu \mathrm{mol}$ dNTPs, $10 \%$ dimethylsulfoxide, $1 \times$ Taq polymerase buffer, $1.5 \mathrm{mM}$ $\mathrm{MgCl}_{2}$ and $0.5 \mathrm{U}$ AmpliTaq Gold (Applied Biosystems, Foster, CA). The PCR condition for MT2A $-5 \mathrm{~A} / \mathrm{G}$ comprised an initiation denaturation step at $94{ }^{\circ} \mathrm{C}$ for $4 \mathrm{~min}$, followed by 30 cycles of $96^{\circ} \mathrm{C}$ for $1 \mathrm{~min}, 61^{\circ} \mathrm{C}$ for $1 \mathrm{~min}, 72{ }^{\circ} \mathrm{C}$ for $1 \mathrm{~min}$ and final extension step at $72{ }^{\circ} \mathrm{C}$ for $10 \mathrm{~min}$. MT2A $-209 \mathrm{~A} / \mathrm{G}$ was amplified 35 cycles at an annealing temperature of $62{ }^{\circ} \mathrm{C}$ for $1 \mathrm{~min}$, and extension at $72{ }^{\circ} \mathrm{C}$ for $10 \mathrm{~min}$. The conditions for MT2A $+838 \mathrm{C} / \mathrm{G}$ was 30 cycles at $61{ }^{\circ} \mathrm{C}$ annealing temperature for $1 \mathrm{~min}$ and extension at $72{ }^{\circ} \mathrm{C}$ for $10 \mathrm{~min}$. Subsequently, RFLP analysis was performed on 20 microliters each of the respective PCR products by subjecting them to the following restriction enzymes: at a $5 \mathrm{U}$ concentration: $\mathrm{Bsg} \mathrm{I}$ (at $37^{\circ} \mathrm{C}$ for $3 \mathrm{~h}$ ) for MT2A $-5 \mathrm{~A} / \mathrm{G}$ and $\operatorname{Sma}$ I (at $25{ }^{\circ} \mathrm{C}$ for $3 \mathrm{~h}$ ) for MT2A - 209A/G (both from New England Biolabs, UK), and Mae III (Roche Molecular Systems, Branchburg, USA) for MT2A $+838 \mathrm{C} / \mathrm{G}$ with $3 \mathrm{U}$ concentration and overnight incubation at $55{ }^{\circ} \mathrm{C}[13-15]$.

In the case of MT2A $-5 \mathrm{~A} / \mathrm{G}$, the lengths of fragments obtained by digestion of each 185-bp fragment by Bsg I were 144 and $41 \mathrm{bp}$ for the A/A genotype, 185, 144 and $41 \mathrm{bp}$ for the A/G type and $185 \mathrm{bp}$ for the G/G genotype. For MT2A - 209A/G, after digestion by Sma I of the PCR products of $246 \mathrm{bp}$ fragment for A/A homozygotes, 131 and 115 bp for $\mathrm{G} / \mathrm{G}$ homozygotes and all three fragments for heterozygotes $\mathrm{A} / \mathrm{G}$ were registered. Analogously, in the case of MT2A $+838 \mathrm{C} / \mathrm{G}$, after digestion by Mae III of the PCR products of 157-bp fragment for A/A homozygotes, 95 and 62 bp for G/G homozygotes and 157, 95 and 62 bp for heterozygotes $\mathrm{A} / \mathrm{G}$ were observed.

The products were analyzed by electrophoresis on $3 \%$ agarose gel and ethidium bromide-stained. Positive and negative controls were included in each gel. Quality control was ensured by including a random $5 \%$ of the samples as duplicates.

\section{Statistical data analysis}

Genotype distributions were evaluated for agreement with Hardy-Weinberg equilibrium by the Chi-square test. All genotype distributions of MT2A fit Hardy-Weinberg equilibrium. Unconditional multiple logistic regression models were used to calculate odds ratios (ORs) and $95 \%$ confidence intervals (CIs) for the association of genotype with breast cancer risk. Genotype data were analyzed with the homozygote of the common allele as the reference group. Variants of homozygotes and heterozygotes were combined to evaluate the dominant effect. For each SNP, trend tests were conducted by assigning the values 1,2 and 3 to homozygous wild type, heterozygous and homozygous variant genotypes, respectively, and by adding these scores as a continuous variable in logistic regression model.

The haplotype effects of the polymorphisms on breast cancer risk were analyzed using the Chaplin 1.2 (genetics. emory.edu) and THESIAS software (www.genecanvas.org). 
All haplotypes were examined simultaneously in regression models with the most common haplotype as the reference. Haplotypes were evaluated for association with breast cancer in unadjusted and adjusted logistic regression models as done for the individual SNPs. All multivariate models were adjusted for age, family history, obesity, smoking status, parity, menopausal status and use of contraceptive and menopausal hormones. Reported $p$ values were two sided. Probabilities were considered significant whenever $p$ value was lower than 0.05 . All analyses were completed using STATA software (version 11.0 StataCorp., Texas, USA).

\section{Results and discussion}

The distributions of socio-demographic characteristics and lifestyle risk factors are shown in Table 1. Our sample is as a whole Caucasian and closely mirrors the Polish population. The cases were slightly older $(54.76 \pm 7.35$ vs. $51.27 \pm 11.18$ years for controls), more likely to use oral contraceptives (64.4 vs. $50.1 \%$ for controls), more likely to be a current smoker (37.1 vs. $26.2 \%$ for controls) and more likely to have a BMI greater or equal than 30 (39.9 vs. $28.9 \%$ for controls).

Genotype and allele distributions for MT2A polymorphisms in 534 breast cancer patients and 556 control subjects are summarized in Table 2. Approximately, $95 \%$ of the PCR-RFLP reactions were successful ( $4.7 \%$ cases and 5.3 controls had unsuccessful PCR reactions). One SNP in MT2A (rs28366003) showed a positive association with breast cancer. Having one copy of the risk allele $(\mathrm{G})$ conferred an estimated $90 \%$ increase in breast cancer in the model adjusted for age, family history, smoking status, BMI, menarche, parity, menopausal status and use of contraceptive and menopausal hormones $(\mathrm{OR}=1.94$, $95 \%$ CI: $\left.1.31-2.90, p_{\text {dominant }}<0.02\right)$. Homozygous variant allele carriers were not present in healthy controls. No other SNP was statistically significantly associated with breast cancer. Four haplotypes were estimated to have a population frequency of at least $5 \%$. One haplotype GAG, including variant allele of rs28366003 SNP, showed evidence of a statistically significantly increased risk of breast cancer in Polish population, with an approximately $50 \%$ increase in risk for $(\mathrm{OR}=1.58, \mathrm{CI}$ : $0.41-6.33$, $p$ global $=0.03)($ Table 3$)$.

In this breast cancer case-control study in a Polish population, we examined the association of three single nucleotide polymorphisms of MT2A gene with the risk of breast cancer. The SNPs analyzed by us concerned A/G transition in the promoter region at loci -5 and -209 (rs28366003 and rs1610216, respectively) and C/G transition in the untranslated region at locus +838 (rs10636).
Table 1 Selected baseline characteristics of breast cancer cases and controls with questionnaire data

\begin{tabular}{|c|c|c|c|}
\hline & $\begin{array}{l}\text { Cases } \\
(n(\%))\end{array}$ & $\begin{array}{l}\text { Controls } \\
(n(\%))\end{array}$ & $p$ \\
\hline \multicolumn{4}{|l|}{ Age (years) } \\
\hline $35-44$ & $123(23.0)$ & $189(34.0)$ & \\
\hline $45-54$ & $133(25.0)$ & $139(25.0)$ & \\
\hline $55-64$ & $150(28.1)$ & $122(21.9)$ & \\
\hline $65-74$ & $96(18.0)$ & $89(16.0)$ & \\
\hline $75-84$ & $32(5.9)$ & $17(3.1)$ & $<0.001$ \\
\hline \multicolumn{4}{|c|}{ Family history of breast cancer ${ }^{a}$} \\
\hline Yes & $64(11.9)$ & $50(9.0)$ & \\
\hline No & $470(88.1)$ & $506(91.0)$ & 0.11 \\
\hline \multicolumn{4}{|l|}{ Obesity $(B M I \geq 30 \mathrm{~kg} / \mathrm{m} 2)^{b}$} \\
\hline Yes & $213(39.9)$ & $161(28.9)$ & \\
\hline No & $321(60.1)$ & $395(71.1)$ & $<0.001$ \\
\hline \multicolumn{4}{|l|}{ Smoking status } \\
\hline Never & $96(18.0)$ & $155(27.9)$ & \\
\hline Former & $240(44.9)$ & $255(45.9)$ & \\
\hline Current & $198(37.1)$ & $146(26.2)$ & $<0.001$ \\
\hline \multicolumn{4}{|l|}{ Menarche (years) } \\
\hline 10 & $11(2.1)$ & $0(0.0)$ & \\
\hline 11 & $101(18.9)$ & $106(19.2)$ & \\
\hline 12 & $171(32.1)$ & $200(35.9)$ & \\
\hline 13 & $144(26.9)$ & $167(30.0)$ & \\
\hline 14 & $91(17.1)$ & $72(12.9)$ & \\
\hline$\geq 15$ & $16(2.9)$ & $11(2.0)$ & $<0.01$ \\
\hline \multicolumn{4}{|l|}{ Used oral contraceptives $^{c}$} \\
\hline Yes & $344(64.4)$ & $283(50.1)$ & \\
\hline No & $190(35.6)$ & $273(49.9)$ & $<0.0001$ \\
\hline \multicolumn{4}{|l|}{ Parity } \\
\hline Nulliparous & $114(21.3)$ & $128(23.0)$ & \\
\hline 1 & $125(23.4)$ & $144(25.9)$ & \\
\hline 2 & $140(26.2)$ & $156(28.0)$ & \\
\hline 3 & $98(18.3)$ & $94(16.9)$ & \\
\hline$\geq 4$ & $57(10.8)$ & $34(6.2)$ & 0.07 \\
\hline Age at menopause $(\text { years })^{\mathrm{d}}$ & $50.1 \pm 4.3$ & $49.8 \pm 4.6$ & 0.23 \\
\hline \multicolumn{4}{|c|}{ Use of menopausal hormones ${ }^{e}$} \\
\hline Never & $308(57.7)$ & $384(69.1)$ & \\
\hline Estrogen & $144(27.0)$ & $94(16.9)$ & \\
\hline Progestin & $32(6.0)$ & $23(4.1)$ & \\
\hline Combined & $50(9.3)$ & $55(9.9)$ & $<0.001$ \\
\hline
\end{tabular}

\footnotetext{
${ }^{a}$ Family history defined as self-reporting of at least one first-degree relative with known breast cancer

${ }^{b}$ Body mass index (BMI) was calculated as current weight in kilograms divided by height in meter square (according to WHO classification)

${ }^{c}$ Regular drug use was defined as self-report use of oral contraceptives for 6 months or longer

${ }^{\mathrm{d}}$ Natural age at menopause was defined as the age at the last menstrual period, which can only be defined retrospectively after at least 12 consecutive months of amenorrhea. This last menstrual period should not be induced by surgery or other obvious causes, such as irradiation or hormone therapy

${ }^{\mathrm{e}}$ Regular drug use was defined as self-report use of menopausal hormones for 6 months or longer
} 
Table 2 Associations between MT2A SNPs and breast cancer risk

\begin{tabular}{|c|c|c|c|c|c|}
\hline SNP genotype & Cases $(\%) /$ controls $(\%)$ & OR $(95 \% \mathrm{CI})^{\mathrm{a}}$ & $p$ & OR $(95 \% \mathrm{CI})^{\mathrm{b}}$ & $p$ \\
\hline \multicolumn{6}{|l|}{$r s 28366003(S N P 1)$} \\
\hline AA & $465(87.1) / 516(92.8)$ & 1.00 (reference) & & 1.00 (reference) & \\
\hline AG & $66(12.3) / 40(7.2)$ & $1.83(1.21-2.77)$ & - & $1.92(1.28-2.81)$ & \\
\hline GG & $3(0.6) / 0(0.0)$ & - & & - & \\
\hline$p$ trend $^{\mathrm{c}}$ & & $<0.001$ & & $<0.01$ & \\
\hline AG or GG vs. $\mathrm{AA}^{\mathrm{d}}$ & $69(12.9) / 40(7.2)$ & $1.91(1.27-2.88)$ & $<0.01$ & $1.93(1.29-2.89)$ & $<0.02$ \\
\hline $\begin{array}{l}\mathrm{AG} \text { or } \mathrm{AA} \text { vs. } \mathrm{GG}^{\mathrm{e}} \\
r s 1610216(S N P 2)\end{array}$ & \multicolumn{4}{|c|}{ rs1610216 (SNP2) } & - \\
\hline AA & $408(76.4) / 402(72.3)$ & 1.00 (reference) & & 1.00 (reference) & \\
\hline AG & $125(23.4) / 153(27.5)$ & $0.80(0.61-1.06)$ & & $0.81(0.63-1.09)$ & \\
\hline GG & $1(0.2) / 1(0.2)$ & $0.98(0.06-15.83)$ & & $1.06(0.09-16.72)$ & \\
\hline$p$ trend $^{\mathrm{c}}$ & & 0.13 & & 0.73 & \\
\hline AG or GG vs. $\mathrm{AA}^{\mathrm{d}}$ & $126(23.6) / 154(27.7)$ & $0.81(0.61-1.06)$ & 0.12 & $0.82(0.64-1.11)$ & 0.24 \\
\hline $\begin{array}{l}\mathrm{AG} \text { or } \mathrm{AA} \text { vs. } \mathrm{GG}^{\mathrm{e}} \\
r s 10636(\mathrm{SNP} 3)\end{array}$ & \multicolumn{4}{|c|}{ rs10636 (SNP3) } & 0.87 \\
\hline GG & $305(57.1) / 280(50.3)$ & 1.00 (reference) & & 1.00 (reference) & \\
\hline GC & $205(38.4) / 253(45.5)$ & $0.74(0.58-0.95)$ & & $0.69(0.52-0.94)$ & \\
\hline $\mathrm{CC}$ & $24(4.5) / 23(4.2)$ & $0.96(0.53-1.74)$ & & $0.91(0.64-1.71)$ & \\
\hline$p$ trend $^{\mathrm{c}}$ & & 0.07 & & 0.17 & \\
\hline $\mathrm{CG}$ or $\mathrm{CC}$ vs. $\mathrm{GG}^{\mathrm{d}}$ & $510(95.5) / 504(90.6)$ & $0.76(0.60-0.97)$ & 0.02 & $0.73(0.57-0.96)$ & 0.06 \\
\hline $\mathrm{CG}$ or $\mathrm{GG}$ vs. $\mathrm{CC}^{\mathrm{e}}$ & $229(42.9) / 301(54.1)$ & $1.09(0.61-1.96)$ & 0.07 & $1.11(0.64-2.03)$ & 0.94 \\
\hline \multicolumn{6}{|l|}{${ }^{a}$ Crude } \\
\hline
\end{tabular}

Table 3 Associations between MT2A haplotypes and breast cancer risk

\begin{tabular}{llll}
\hline Haplotypes (SNP1-SNP3) & Cases $(\%) /$ controls $(\%)$ & OR $(95 \% \mathrm{CI})^{\mathrm{a}}$ & OR (95\% CI) \\
\hline A-A-G & $167(31.27) / 184(33.09)$ & 1.00 (reference) & $1.00($ reference) \\
G-A-G & $142(26.58) / 121(21.77)$ & $1.54(0.38-6.28)$ & $1.58(0.41-6.30)$ \\
A-A-C & $118(22.10) / 134(24.10)$ & $0.84(0.37-1.65)$ & $0.83(0.36-1.67)$ \\
A-G-C & $106(19.85) / 117(21.04)$ & $0.82(0.42-2.19$ & $0.81(0.41-2.08)$
\end{tabular}

a Crude

b Adjusted for age, family history, smoking status, BMI, menarche, parity, menopausal status and use of contraceptive and menopausal hormones

Our results suggest that one of three SNPs (rs28366003) influences significantly susceptibility of breast cancer.

MT2A $-5 \mathrm{~A} / \mathrm{G}$ single nucleotide polymorphism (rs28366003) is located at the core promoter region of MT2A gene between the TATA box and the site of initiation of transcription. This SNP is an A/G substitution located in the center of the consensus sequence TGCA CTC. This conversion in turn may reduce the binding, to the core promoter region, of a nuclear protein that is involved in MT2A gene basic transcription [13].
In the literature, there are a few studies concerning rs1610216, rs28366003r and rs10636 polymorphisms of $M T 2 A$. The $-5 \mathrm{~A} / \mathrm{G}$ polymorphism has been studied in Japanese and Turkish populations and genotype frequencies of AA, AG and GG are 82, 17 and 0,9 \% for Japanese and $87,12,3$ and $0,7 \%$ for Turkish $[13,16]$. McElroy et al. [17] determined the frequency of the $A$ and $G$ alleles at rs28366003 in the promoter region of MT2A in White and Black females in the Midwestern United States. The frequency of the $\mathrm{G}$ allele was $1.1 \%$ for Blacks and $6.4 \%$ for 
Whites. Data demonstrated that the G allele is not common in both the Midwestern US Black and White female population and is less frequent than that reported for an Asian population. In our study regarding $-5 \mathrm{~A} / \mathrm{G}$ polymorphism, the allelic frequencies of the $\mathrm{A} / \mathrm{A}, \mathrm{A} / \mathrm{G}$, and $\mathrm{G} / \mathrm{G}$ genotypes in the control group (healthy subjects) were 92.8, 7.2 and $0 \%$, respectively. Thus, similarly to the results obtained in Midwestern US, female population frequency of $\mathrm{G}$ allele was rather low in Polish women population.

The rs 28366003 polymorphism was extensively studied in Turkish population in relation to cadmium and other metals levels in tissues and blood [18-20]. The other metallothionein $2 \mathrm{~A}$ gene polymorphisms have been studied for their associations with risk for a variety of diseases. Giacconi et al. [14] reported a significant relationship between -209A/G MT2A polymorphism, diabetes type II and atherosclerosis. The positive association between $+838 \mathrm{C} / \mathrm{G} M T 2 A$ polymorphism and carotid artery stenosis in elderly people was also found [15]. Yang et al. [21] showed that rs10636 was significantly associated with incidence of type 2 diabetes mellitus with neuropathy in Chinese population.

The role of MT in carcinogenesis and progression of breast cancer is not fully understood but it is suggested that metallothionein may play a role in cell proliferation, apoptosis and differentiation which are very important processes in carcinogenesis. The MT2A expression in breast cancer tissue correlates with increased proliferation indicated by Ki-67 immunopositivity [22]. Moreover, it was demonstrated that overexpression of MT2A in breast MCF-7 cells resulted in a twofold increase in cell multiplication [23]. Lim et al. [24] suggested that MT2A could plausibly modulate cell cycle progression from G1 to $\mathrm{S}$ phase via the ATM/Chk2/cdc25A pathway. Antisense down-regulation of MT2A was associated with increased apoptosis [11]. It is suggested that metallothionein participates in the regulation of apoptosis by inhibiting cell death and improving cell survival in periods of stress due to its ability to prevent oxidative damage and ability to interact with different apoptotic signal mechanisms [25, 26]. Metallothionein may also play a role in cancer progression. Kim et al. [27] have shown that metallothionein overexpression in MDA-MB-231 cells increased the expression of metalloproteinase-9. They suggest that up-regulation of MMP-9 is one of the mechanisms by which MT2A promotes invasion of breast cancer cells.

Taking into account these molecular and cellular studies, it seemed to be very likely that genetic polymorphisms in the MT genes may affect susceptibility to breast cancer. In the literature, there is only one study of MT2A polymorphism concerning breast cancer patients. Seibold et al. [28] have found the association of MT2A polymorphisms with postmenopausal breast cancer risk. The two significant SNPs (rs1008766 and rs1580833) analyzed by them are located in flanking regions of the gene. Our results suggest that another SNP (rs28366003) might also be associated with breast cancer risk.

There are several limitations of our study. One of them is the small sample size and the small number of homozygote individuals with rare alleles which may affect odds ratio estimates. Our results are limited to Caucasian women born and living in central Poland. Further studies are needed in other populations. Moreover, all cases used in this study are invasive ductal breast cancer, the most common type of invasive breast cancer. Our findings may not generalize to less frequently diagnosed invasive breast cancer subtypes.

While confirmation of our results in other populations will be necessary, the results of this study are consistent with other studies suggesting the potential role of MT2A gene in breast carcinogenesis. Since the -5 position is located in the promoter region, it is possible that the substitution A/G produces allele-specific MT2A gene expression. Our future research will address just this issue in relation to the concentration of metals in breast cancer tissue. In summary, we found that in Polish population, the $-5 \mathrm{~A} / \mathrm{G}$ (rs28366003) polymorphism in the MT2A gene may play role in susceptibility to breast cancer.

Acknowledgments This work was supported, in part, by the statutory fund for the Department of Cytobiochemistry, University of Łódź.

Conflict of interest The authors declare that they have no conflict of interest.

Open Access This article is distributed under the terms of the Creative Commons Attribution License which permits any use, distribution, and reproduction in any medium, provided the original author(s) and the source are credited.

\section{References}

1. Coyle P, Philcox JC, Carey LC, Rofe AM (2002) Metallothionein: the multipurpose protein. Cell Mol Sci 59:627-647

2. Thirumoorthy N, Manisenthil Kumar KT, Shyam Sunder A, Panayappan L, Chatterjee M (2007) Metallothionei: an overview. World J Gastroenerol 13:993-996

3. Thirumoorthy N, Shyam Sunder A, Manisenthil Kumar K, Senthil Kumar M, Ganesh G, Chatterjee M (2011) A review of metallothionein isoforms and their role in pathophysiology. World J Surg Oncol 9:54. doi:10.1186/1477-7819-9-54

4. Sabolić I, Breljak D, Skarica M, Herak-Kramberger CM (2010) Role of metallothionein in cadmium traffic and toxicity in kidneys and other mammalian organs. Biometals 23:897-926

5. Pedersen MØ, Larsen A, Stoltenberg M, Penkowa M (2009) The role of metallothionein in oncogenesis and cancer prognosis. Prog Histochem Cytochem 44:29-64

6. Namdarghanbari M, Wobig W, Krezoski S, Tabatabai NM, Petering DH (2011) Mammalian metallothionein in toxicology, 
cancer, and cancer chemotherapy. J Biol Inorg Chem 16:10871101

7. Cherian MG, Jayasurya A, Bay BH (2003) Metallothionein in human tumors and potential roles in carcinogenesis. Mutat Res 533:201-209

8. Haq F, Mahoiney M, Kropatnicki J (2003) Signaling events for metallothionein induction. Mutat Res 533:211-226

9. Theocharis SE, Margeli AP, Kilijanienko JT, Kouraklis GP (2004) Metallothionein expression in human neoplasia. Histopthology 45:103-118

10. Dziegiel P (2004) Expression of metallothionein in human cells. Pol J Pathol 55:3-12

11. Jin R, Huang J, Tan P, Bay B (2004) Clinicopathological significance of metallothioneins in breast cancer. Pathol Oncol Res 10:74-79

12. Bay BH, Jin R, Huang J, Tan PH (2006) Metallothionein as a prognostic biomarker in breast cancer. Exp Biol Med (Maywood) 231:1516-1521

13. Kita K, Miura M, Yoshida M et al (2006) Potential effect on cellular response to cadmium of a single-nucleotide $A \rightarrow G$ polymorphism in the promoter of the human gene for metallothionein IIA. Hum Genet 120:553-560

14. Giacconi R, Cipriano C, Muti E et al (2005) Novel -209A/G MT2A polymorphism in old patients with type 2 diabetes and atherosclerosis: relationship with inflammation (IL-6) and zinc. Biogerontology 6:407-413

15. Giacconi R, Muti E, Malavolta $\mathrm{M}$ et al (2007) The $+838 \mathrm{C} / \mathrm{G}$ MT2A polymorphism, metals, and the inflammatory/immune response in carotid artery stenosis in elderly people. Mol Med $13: 388-395$

16. Kayaalti Z, Söylemezoglu T (2010) The polymorphism of core promoter region om metallothionein 2A-metal binding protein in Turkish population. Mol Biol Rep 37:185-190

17. McElroy JA, Bryda EC, McKay SD, Schnabel RD, Taylor JF (2010) Genetic variation at a metallothionein 2A promoter singlenucleotide polymorphism in white and black females in Midwestern United States. J Toxicol Environ Health A 73:1283-1287

18. Kayaaltı Z, Aliyev V, Söylemezoğlu T (2011) The potential effect of metallothionein $2 \mathrm{~A}-5 \mathrm{~A} / \mathrm{G}$ single nucleotide polymorphism on blood cadmium, lead, zinc and copper levels. Toxicol Appl Pharmacol 256:1-7

19. Kayaalti Z, Mergen G, Söylemezoğlu T (2011) Effect of metallothionein core promoter region polymorphism on cadmium, zinc and copper levels in autopsy kidney tissues from a Turkish population. Toxicol Appl Pharmacol 245:252-255

20. Tekin D, Kayaaltı Z, Söylemezoğlu T (2012) The effects of metallothionein $2 \mathrm{~A}$ polymorphism on lead metabolism: are pregnant women with a heterozygote genotype for metallothionein $2 \mathrm{~A}$ polymorphism and their newborns at risk of having higher blood lead levels. Int Arch Occup Environ Health 85:631-637

21. Yang L, Li H, Yu T et al (2008) Polymorphisms in metallothionein-1 and -2 genes associated with the risk of type 2 diabetes mellitus and its complications. Am J Physiol Endocrinol Metab 294:E987-E992

22. Jin R, Chow VT, Tan PH, Dheen ST, Duan W, Bay BH (2002) Metallothionein 2A expression is associated with cell proliferation in breast cancer. Carcinogenesis 23:81-86

23. Abdel-Mageed A, Agrawal KC (1997) Antisense down-regulation of metallothionein induces growth arrest and apoptosis in human breast carcinoma cells. Cancer Gene Ther 4:199-207

24. Lim D, Jocelyn KM, Yip GW, Bay BH (2009) Silencing the Metallothionein-2A gene inhibits cell cycle progression from G1to S-phase involving ATM and cdc25A signaling in breast cancer cells. Cancer Lett 276:109-117

25. Cai L, Klein JB, Kang YJ (2000) Metallothionein inhibits peroxynitriteinduced DNA and lipoprotein damage. J Biol Chem 275:38957-38960

26. Shimoda R, Achanzar WE, Qu W et al (2003) Metallothionein is a potential negative regulator of apoptosis. Toxicol Sci 73:294-300

27. Kim HG, Kim JY, Han EH et al (2011) Metallothionein-2A overexpression increases the expression of matrix metalloproteinase-9 and invasion of breast cancer cells. FEBS Lett 585:421-428

28. Seibold P, Hein R, Schmezer P et al (2011) Polymorphisms in oxidative stress-related genes and postmenopausal breast cancer risk. Int J Cancer 129:1467-1476 